\title{
A Sociosemiotic Approach of experienced and Desired Leisure. Young People Express Themselves Through Images.
}

\author{
Anastasia Christodoulou
}

Aristotle University of Thessaloniki E-mail:nata@itl.auth.gr

\section{Eleni Kartsaka}

Art Historian

\section{Argyris Kyridis}

Aristotle University of Thessaloniki E-mail:akiridis@uowm.gr

Doi:10.5901/ajis/2013.v2n1p21

\section{Abstract}

Young people are society's driving force. They build the future and ensure its cultural, historical and biological continuity. Given the important role they play, their ability to manage their own leisure time is especially significant as regards its impact on society. A person's leisure is a concept whose dimensions and boundaries are constantly in flux. It is part of everyday life, a form of personal expression and selffulfillment, and its use may have a positive or negative impact on a person and their environment (Ghikopoulos \& Christodoulou, 2007; Myrizakis, 1997). The aim of this research is to explore the manner in which adolescents perceive the experienced and desired limits to their own leisure time. More specifically, the study focused on the artistic (paintings and drawings) and verbal (accompanying written texts) codes that young people use to describe the limits of two living conditions, the leisure that they experience and the leisure that they desire. The artistic code was chosen in addition to the verbal code because these days, particularly where young people are concerned, images prevail (Willinsky, 1990). Socio-semiotics is chosen as the tool of analysis, since artistic creation, as an interpretation of the concept image', is a metalanguage, a dynamic channel that young people use to convey leisure time messages (Danesi, 2000; Halliday, I978; Randviir \& Cobley 2010). This two-pronged research project was based on the semiotic study and analysis of data (Lagopoulos \& Boklund-Lagopoulou, 1992; Christodoulou, 2003) obtained from the artistic and verbal texts of adolescents between twelve and fifteen years of age. To begin with, the adolescents depicted aspects of their daily leisure artistically and attempted to accompany their artwork with a brief verbal description. They then chose photographs somehow depicting their ideal leisure time from a chart of preselected pictures whose subjects were obtained from the literature (thematic caterogies). The researchers had preselected these pictures as a means of exploring the concept of desired leisure. The study was completed in three stages: (a) a theoretical framework of free time and its analysis, (b) data analysis and (c) conclusions about the meanings that leisure (experienced and desired) has for young people.

Keywords: experienced leisure, desired leisure, Greece, young people, images

\section{Theoretical introduction of the study}

When looking at the available literature on leisure, one realizes that there is no shortage of views and 
stances on the subject, as it has to do not only with the culture of everyday life but with a lot of axes of the definition of culture (Danesi \& Perron, 1999). This research has explored leisure in terms of its definition, analysis and significance of young people's relationship with it.

In the literature, then, leisure is defined based on a number of parameters. For example, leisure is the time that a person devotes to various activities when not at work (Triantafyllidis, 1998). Freedom of choice during leisure seems to be the dominant theme in the above definition (Kelly, I98I). It is unclear whether a person's activities during that time are carefree (Kouthouris, 2006) and non-obligatory (Byrne, Nixon, Mayock, \& Whyte, 2006).

According to Silbereisen (2004), leisure can be divided into two categories: (a) inactive leisure, which does not make a person socially active, for example watching television or listening to music, and (b) active leisure, which enhances socialisation, such as hobbies and sports. 'Structural recreation', as Coatsworth et al. (2005) and Hendry et al. (I993 and 2003) defined it, seems to fall within Silbereisen's second category, since it refers to activities that emphasise skill development.

A different categorisation divides leisure into rest and relaxation, entertainment, information, education, participation in social events, creativity, and freedom from family, professional and social obligations (Krasanakis, 1984). Leisure is often indirectly associated with consumer practices, such as shows and entertainment, which leads to the need to find new sources of income linked to mass culture and the search for enjoyment (Riesman, in Koronaiou, 1996).

The above observation does not seem to apply to the younger age group, since young people do not associate free time with particular activities, but rather with hanging around (Byrne et al., 2006). Of course, there are dangers inherent in perceiving leisure as time to hang around - dangers associated with the 'improper' management of free time and especially with idleness and inactivity. Research has shown that $90 \%$ of delinquent behaviour occurs during free time, which is an argument in favour of its value and proper management (Koronaiou, 1996; Trainor et. al., 2010; Larson and Verma, in Byrne et al., 2006). Research conducted by Shaw et al. (1996) on how fifteen year olds in Canada spend their free time showed that they mainly hang around, wasting time. Similar evidence was obtained by George and Chaskin (2004) in their research on fourteen year olds in Chicago, only one quarter of which spend their leisure doing structured activities. The other three quarters prefer carefree and unstructured leisure.

Theoretically, leisure activities are a springboard for young people's participation in society and foster the conditions needed for adolescents to shape their own identities (Caldwell \& Darling, in Trainor et al., 2010; Chtouris, Zissi, Papanis, \& Rontos, 2006). There are activities that educate (visits to museums and monuments) and activities that entertain (holidays, games, sports) (Christodoulou, 2003:67). Interestingly, research conducted by Mahoney and Cairns (1997) showed that pupils who took part in leisure activities at their school were less likely to quit school.

However, in practice and for a variety of reasons, today's youth living in Greece does not often get the chance to take part in leisure activities that entertain. One major reason is that they devote their time to gaining skills that will make them more employable in the future. Moreover, the paper presented by Eccles et al. (2003) on extracurricular activities showed that such activities aid personal development. It appears that leisure activities are often also dependent on basic social factors such as sex and social class, although, admittedly, there has not been much research on the subject (Roberts and Parsells, I994; Hendry et al., 2003; Hochschild, I997: 2I5; Robinson \& Godbey, 1997). Thus, young people do not have time to take part in activities that educate (visits to archaeological sites and monuments) unless they are part of a school's cultural programme. Moreover, interpersonal communication (active communication) has become weaker and is being replaced by Internet communication (passive communication), with very little time devoted to sports and activities outside the home (United Nations World Youth Report 2005). 
A survey conducted in 2003, via questionnaire, on young people between fifteen and twenty-nine years of age living in urban and semi-urban areas in Greece revealed that their main leisure activities include spending time with family and friends, listening to music and watching television. There was little interest in hobbies and physical exercise, with volunteering and participation in youth clubs least popular of all (Chtouris et al., 2006) - data which is also evident in this research. The same conclusions have been drawn from a survey of children and adolescents from low-income families in England, who said that they spend their time watching television out of necessity and not because they are ultimately interested in it (Ridge, in Byrne et al., 2006).

\section{Method of analysis}

This study aims to (a) have adolescents illustrate their leisure time, (b) determine the limits to leisure during adolescence and (c) determine the extent to which adolescents' (boys' and girls') experienced leisure converges towards or strays from their desired leisure.

The meaning system chosen for the purposes of this study was the artistic text, with the verbal text serving a supplementary role. We focused more on the iconic rather than the verbal system because most sociological survey results are drawn from written questionnaires. Our novel approach was adopted as a result of our observation that the emerging and dominant form of communication between young people today increasingly involves images (MMS, SMS, and internet). As a result, we expected that they would find conveying meanings and ideas using images a familiar concept.

The survey, which took place from March to May 2010, was based on the study and semiotic analysis of artistic and verbal texts and involved one hundred adolescents (fifty boys and fifty girls) from western Thessaloniki.

More specifically, the survey focused on two aspects: (a) experienced leisure and (b) desired leisure. The experienced leisure aspect focused on the analysis of one hundred artistic creations and their accompanying texts, through which the adolescents conveyed and described how they perceive the free time they experience (see two of the children's artwork, figures I and 2). The adolescents were instructed to depict moments in their experienced leisure time using any materials and techniques they chose. They were not given any further guidance so that their creations would be spontaneous.

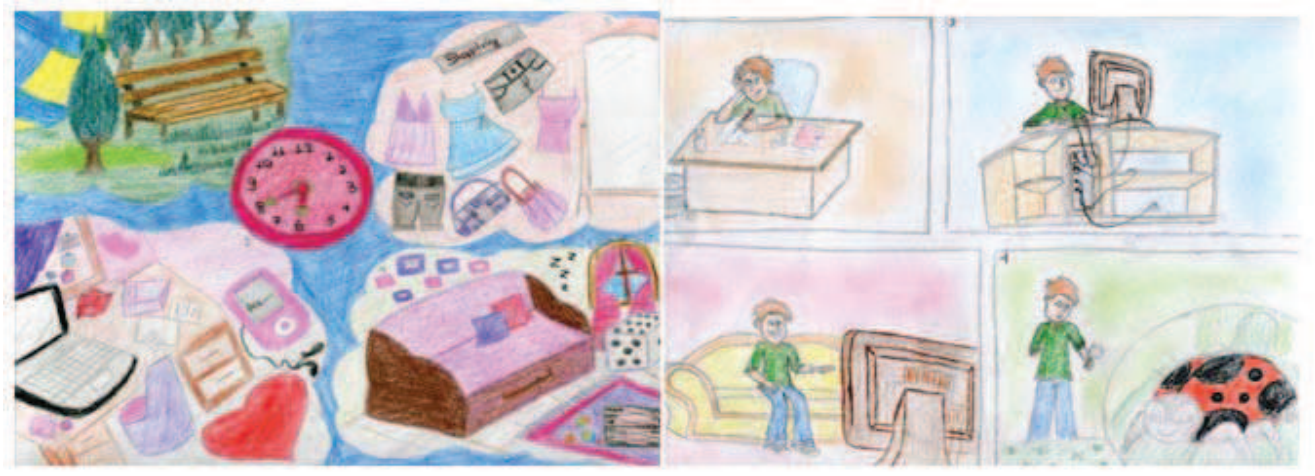

Fig. I. How I spend my free time (girl)

Fig. 2. How I spend my free time (boy)

The second aspect, desired leisure, focused on the selection of pictures from a preselected chart. There were forty-one options, namely thirty-nine photographs representing categorised leisure activities 
that young people would ideally choose, as well as two additional options, 'something else' and 'nothing'. The photographs portray leisure categories obtained from the general literature (Christodoulou, 2003, Lagopoulos \& Bolkund-Lagopoulou 1992). They are related to official culture, the arts, language and literature, sports, education and entertainment. More specifically, the categories examined are listed below in the order in which they appear in the preselected chart (Figure 3): (I) theatre, (2) skateboarding or another sport, (3) museums or other art and cultural centres, (4) Internet cafés, (5) computers, (6) graffiti, (7) volunteer groups, (8) family, (9) funfair, (I0) cinema, (II) shopping centres, (I2) excursions, (I3) basketball or other sports, (I4) television, (I5) football matches, (I6) books, poems, prose, (I7) chess or other intellectual games, (I8) foreign languages, (I9) friends and interpersonal relationships, (20) scouts, (2I) concerts, festivals or other events, (22) shopping, (23) water sports, (24) painting or other hobbies, (25) church, Sunday school, religious events, (26) rest and relaxation, (27) cycling, (28) hanging out with friends, (29) electronic games, PlayStation, (30) parties, (3I) coffee shops and restaurants, (32) playing in the neighbourhood with friends, (33) chatting with friends on the telephone, (34) taking care of animals, (35) playing musical instruments, (36) taking care of my appearance, (37) going to the gym, (38) going for walks on my own, (39) dancing, (40) nothing, (4I) something else.

An analysis of the two aspects, experienced leisure and desired leisure, and the data obtained from the survey are presented below.

\section{Data and analysis}

The research and analysis of leisure have an important role to play in cultural growth. In modern sociological thought, leisure is a paradigmatic field for the study of social structures, meanings and lifestyles, since it records and analyses today's dominant social time.

Having and utilizing free time leads to social growth and improved quality of life, creating well rounded young people and a well rounded society in general. It is true that this study has focused on leisure as young people perceive it (primary source), rather than on the way it is manifested in the social sphere (secondary source).

The research results are presented below, with the scope of the subject in mind and having taken into consideration the research objective and goals and the method of analysis applied. The analysis of the data obtained from the iconic communication system resulted in an overall table (Table I), which presents the selected categories of experienced (EL) and desired leisure (DL) for all the individuals (boys and girls) as percentages. The codes in the table below are grouped in the order in which they appear in the preselected chart of photographs (see Figure 3). The leisure activities were grouped in broader categories based on the key principles of thematic content analysis, with the theme being the unit of analysis (Bardin, 1977; Curley, I990; Weber, 1990, Veron, I98I; Lasswell et al. I965; Mucchieli, I998; Grawitz, I98I).

Table I. Overall table of experienced and desired leisure

\begin{tabular}{|c|c|c|c|c|}
\hline \multirow{2}{*}{\multicolumn{2}{|c|}{ Leisure Activities }} & \multicolumn{2}{|c|}{ Boys } & \multicolumn{2}{c|}{ Girls } \\
\cline { 2 - 5 } & EL & DL & EL & DL \\
\cline { 2 - 5 } & $\%$ & $\%$ & $\%$ & $\%$ \\
\hline Entertainment & 20.4 & 163.9 & 23.2 & 180.8 \\
\hline I. Theatre & 0.0 & 4.9 & 0.0 & 14.9 \\
\hline
\end{tabular}




\begin{tabular}{|c|c|c|c|c|}
\hline 3. Museums, other art and cultural centres & 0.0 & 0.0 & 0.0 & 8.5 \\
\hline IO. Cinema & 5.6 & 65.6 & 17.9 & 59.6 \\
\hline 15. Football matches & 14.8 & 57.4 & 3.6 & 36.2 \\
\hline 21. Concerts, festivals or other events & 0.0 & 36.1 & 1.8 & 61.7 \\
\hline Sports & 92.6 & 201.6 & 30.4 & 166.0 \\
\hline 2. Skateboarding or another sport & 5.6 & 32.8 & 7.1 & 23.4 \\
\hline 13. Basketball or other sports & 59.3 & 52.5 & 14.3 & 29.8 \\
\hline 23. Water sports & 5.6 & 37.7 & 1.8 & 25.5 \\
\hline 37. Gym & 5.6 & 37.7 & 0.0 & 38.3 \\
\hline 39. Dance or gymnastics & 1.9 & 3.3 & 5.4 & 25.5 \\
\hline 27. Cycling & 14.8 & 37.7 & 1.8 & 23.4 \\
\hline Computers & 79.6 & 68.9 & 82.2 & 44.7 \\
\hline 4. Internet cafés & 5.6 & 29.5 & 5.4 & 10.6 \\
\hline 5. Time on the computer & 74.1 & 39.3 & 76.8 & 34.0 \\
\hline Creative Activities & 42.6 & 39.3 & 60.7 & 63.8 \\
\hline 6. Graffiti & 0.0 & 23.0 & 1.8 & 21.3 \\
\hline 16. Reading books or writing poems or prose & 37.0 & 3.3 & 48.2 & 19.2 \\
\hline 24. Painting or other hobbies & 5.6 & I3.I & 10.7 & 23.4 \\
\hline Playing & 3.7 & 65.6 & 12.5 & 63.8 \\
\hline 32. Playing in the neighbourhood with friends & 0.0 & 16.4 & 5.4 & 10.6 \\
\hline 17. Playing chess or other intellectual games & 3.7 & 8.2 & 5.4 & 4.3 \\
\hline 9. Funfair & 0.0 & 41.0 & 1.8 & 48.9 \\
\hline Television & 61.1 & $\mathrm{I} 8.0$ & 55.4 & 14.9 \\
\hline 14. Television & 61.1 & I8.0 & 55.4 & 14.9 \\
\hline Electronic games & 16.7 & 50.8 & 3.6 & 17.0 \\
\hline 29. PlayStation or other electronic games & 16.7 & 50.8 & 3.6 & 17.0 \\
\hline Friends and family & 38.9 & 86.9 & 62.5 & I68.I \\
\hline 8. Time with family & 5.6 & I8.0 & 7.1 & 23.4 \\
\hline 19. Friends and interpersonal relationships & 0.0 & 16.4 & 1.8 & 48.9 \\
\hline 28. Hanging out with friends & 29.6 & 47.5 & 30.4 & 63.8 \\
\hline 33. Telephone & 3.7 & 4.9 & 23.2 & 31.9 \\
\hline Personal Time & 27.7 & 57.4 & 33.9 & II 0.6 \\
\hline 26. I would like rest and relaxation & 24.1 & 39.3 & I6.I & 59.6 \\
\hline 38. Going for walks or spending time on my own & 3.7 & 18.0 & 17.9 & 51.1 \\
\hline Recreation & 70.4 & 103.3 & 83.9 & 178.7 \\
\hline 30. Parties & 0.0 & 31.2 & 0.0 & 59.6 \\
\hline
\end{tabular}




\begin{tabular}{|l|c|c|c|c|}
\hline 31. Coffee shops and restaurants & 22.2 & 31.2 & I4.3 & 38.3 \\
\hline 35. Music & 48.2 & 39.3 & 66.1 & 31.9 \\
\hline 36. Taking care of my appearance & 0.0 & 1.6 & 3.6 & 48.9 \\
\hline Group Activities & 3.7 & 95.1 & 3.6 & 106.4 \\
\hline 7. Volunteer groups & 0.0 & 21.3 & 0.0 & 19.2 \\
\hline I2. Trips and excursions & 3.7 & 57.4 & 3.6 & 78.7 \\
\hline 20. Scouts & 0.0 & 6.6 & 0.0 & 6.4 \\
\hline 25. Church, Sunday school, religious events & 0.0 & 9.8 & 0.0 & 2.1 \\
\hline Shopping & 1.9 & 22.9 & 25.0 & 127.7 \\
\hline II. Hanging out at shopping centres & 0.0 & 16.4 & 0.0 & 57.5 \\
\hline 22. Shopping & 1.9 & 6.6 & 25.0 & 70.2 \\
\hline Supplementary Education & 0.0 & 4.9 & 0.0 & 6.4 \\
\hline I8. Learning foreign languages & 0.0 & 4.9 & 0.0 & 6.4 \\
\hline Taking Care of Animals & 0.0 & 19.7 & 0.0 & 25.5 \\
\hline 34. Animals & 0.0 & 19.7 & 0.0 & 25.5 \\
\hline Something Else & 20.4 & 6.6 & 10.7 & 4.3 \\
\hline
\end{tabular}

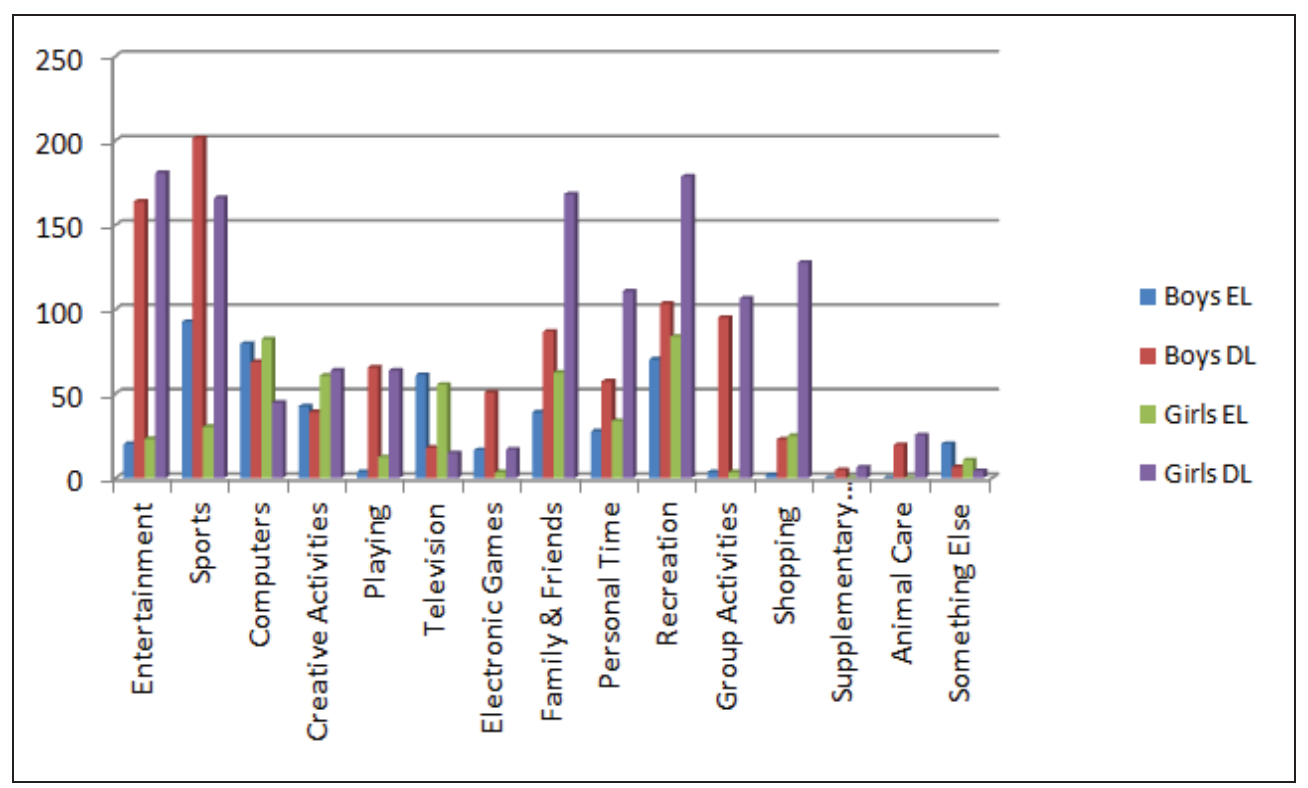

From the analysis of the above table, we observe that there are three types of relationship as regards experienced leisure and desired leisure for boys and girls, as shown in detail below. Reflective learners learn more effectively when they have time to consider options before responding whereas impulsive learners are able to respond immediately and take risks. 
(a) Categories with zero or low rates of experienced leisure and high rates of desired leisure $(E L<D L)$

For boys, EL is zero in $34 \%$ of the codes (Table 2).

Table 2. Categories with zero rates of experienced leisure (boys)

\begin{tabular}{|l|c|c|}
\hline Categories (Boys) & EL \% & DL \% \\
\hline Funfair & 0.00 & 40.98 \\
\hline Concerts, festivals or other events & 0.00 & 36.07 \\
\hline Parties & 0.00 & 31.15 \\
\hline Graffiti & 0.00 & 22.95 \\
\hline Volunteer groups & 0.00 & 21.31 \\
\hline Animals & 0.00 & 19.67 \\
\hline Hanging out at shopping centres & 0.00 & 16.39 \\
\hline Friends and interpersonal relationships & 0.00 & 16.39 \\
\hline Playing in the neighbourhood with friends & 0.00 & 16.39 \\
\hline Church, Sunday school, religious events & 0.00 & 9.84 \\
\hline Scouts & 0.00 & 6.56 \\
\hline Theatre & 0.00 & 4.92 \\
\hline Learning foreign languages & 0.00 & 4.92 \\
\hline Taking care of appearance & 0.00 & 1.64 \\
\hline
\end{tabular}

We note from this table that boys would very much like to have fun, go to festivals and parties, take part in volunteer groups and do graffiti $(40.98 \%-21.31 \%)$. They would like to take care of animals, go to shopping centres, make friends and play in the neighbourhood to a lesser degree $(19.00 \%$ - $10.00 \%$ ), and reveal little willingness to go to church, the theatre, learn foreign languages or spend time on their appearance $(9.00 \%-1.00 \%)$.

As regards experienced leisure, Table 3 indicates that boys experience their desired leisure activities at much lower rates.

Table 3. Categories with low rates of experienced leisure (boys).

\begin{tabular}{|l|c|c|}
\hline Categories (Boys) & EL \% & DL \% \\
\hline Cinema & 5.56 & 65.57 \\
\hline Trips and excursions & 3.70 & 57.38 \\
\hline Football matches & $\mathrm{I} 4.8 \mathrm{I}$ & 57.38 \\
\hline PlayStation or other electronic games & 16.67 & 50.82 \\
\hline Hanging out with friends & 29.63 & 47.54 \\
\hline Rest and relaxation & 24.07 & 39.34 \\
\hline Water sports & 5.56 & 37.70 \\
\hline Gym & 5.56 & 37.70 \\
\hline Cycling & $\mathrm{I} 4.8 \mathrm{I}$ & 37.70 \\
\hline Skateboarding or another sport & 5.56 & 32.79 \\
\hline
\end{tabular}




\begin{tabular}{|l|c|c|}
\hline Coffee shops and restaurants & 22.22 & $3 \mathrm{I} . \mathrm{I5}$ \\
\hline Internet cafés & 5.56 & $29.5 \mathrm{I}$ \\
\hline Going for a walk or spending time on my own & 3.70 & $\mathrm{I} .03$ \\
\hline Time with family & 5.56 & $\mathrm{I} .03$ \\
\hline Painting or other hobbies & 5.56 & $\mathrm{I} 3 . \mathrm{II}$ \\
\hline Playing chess or other intellectual games & 3.70 & 8.20 \\
\hline Shopping & 1.85 & 6.56 \\
\hline Telephone & 3.70 & 4.92 \\
\hline Dance or gymnastics & $\mathrm{I} .85$ & 3.28 \\
\hline
\end{tabular}

Based on the above table, boys experience categories that they would like to experience more at low rates $(1 \%-30 \%)$. More specifically, they would very much like to go to the cinema, on trips and excursions, to football matches, play games and play with friends $(65 \%-40 \%)$. They would like rest and relaxation, going to the gym, cycling or other sports and going to coffee shops and Internet cafés to a lesser extent $(39 \%-20 \%)$, and are less likely to want to spend time with family, paint, go shopping, dance or do gymnastics (19\%-3\%).

Where girls are concerned, they do not experience some categories at all (twenty-four of the total number of categories), but would like to experience them (Table 4).

Table 4. Categories with zero rates of experienced leisure (girls)

\begin{tabular}{|l|c|c|}
\hline Categories (Girls) & EL \% & DL \% \\
\hline Parties & 0.00 & 59.57 \\
\hline Hanging out at shopping centres & 0.00 & 57.45 \\
\hline Gym & 0.00 & 38.30 \\
\hline Animals & 0.00 & 25.53 \\
\hline Volunteer Groups & 0.00 & 19.15 \\
\hline Theatre & 0.00 & 14.89 \\
\hline Museums, other art and cultural centres & 0.00 & $8.5 \mathrm{I}$ \\
\hline Learning foreign languages & 0.00 & 6.38 \\
\hline Scouts & 0.00 & 6.38 \\
\hline Church, Sunday school, religious events & 0.00 & 2.13 \\
\hline
\end{tabular}

From the above table, we observe that girls would really like to go to parties, hang out at shopping centres, go to gym and take care of animals $(40 \%-20 \%)$. They are less interested in volunteering and going to the theatre and museums (19\% - I0\%), and show little willingness to learn foreign languages, join the scouts or go to church $(9 \%-\mathrm{I} \%)$.

We also note from Table 5 that girls experience categories that they would like to experience more at low rates $(5 \%-31 \%)$. More specifically, they would really like to go on trips and excursions, go shopping, take care of their appearance, hang out with friends, and go to concerts, the cinema, the funfair and coffee shops $(78 \%-38 \%)$. They are less interested in rest and relaxation, going to football matches, chatting on the phone, playing basketball or other sports, dancing or doing gymnastics, spending time with family, painting and doing graffiti $(36 \%-21 \%)$, and show little interest in PlayStation and other electronic games, internet cafés and playing in the neighbourhood $(21 \%-10 \%)$. 
Table 5. Categories with low rates of experienced leisure (girls)

\begin{tabular}{|l|c|c|}
\hline Categories (Girls) & EL \% & DL \% \\
\hline Trips and excursions & 3.57 & 78.72 \\
\hline Shopping & 25.00 & $70.2 \mathrm{I}$ \\
\hline Hanging out with friends & 30.36 & 63.83 \\
\hline Concerts, festivals or other events & $\mathrm{I} .79$ & $6 \mathrm{I} .70$ \\
\hline Rest and relaxation & $\mathrm{I} 6.07$ & 59.57 \\
\hline Cinema & $\mathrm{I} 7.86$ & 59.57 \\
\hline Going for a walk or spending time on my own & $\mathrm{I} 7.86$ & $5 \mathrm{I} .06$ \\
\hline Funfair & $\mathrm{I} .79$ & 48.94 \\
\hline Friends and interpersonal relationships & $\mathrm{I} .79$ & 48.94 \\
\hline Taking care of my appearance & 3.57 & 48.94 \\
\hline Coffee shops and restaurants & $\mathrm{I} .29$ & 38.30 \\
\hline Football matches & 3.57 & 36.17 \\
\hline Telephone & $23.2 \mathrm{I}$ & $3 \mathrm{I} .9 \mathrm{I}$ \\
\hline Basketball or other sports & $\mathrm{I} .29$ & 29.79 \\
\hline Water sports & $\mathrm{I} .79$ & 25.53 \\
\hline Dance or gymnastics & 5.36 & 25.53 \\
\hline Cycling & $\mathrm{I} .79$ & 23.40 \\
\hline Skateboarding or other sports & 7.14 & 23.40 \\
\hline Time with family & 7.14 & 23.40 \\
\hline Painting or other hobbies & $10.7 \mathrm{I}$ & 23.40 \\
\hline Graffiti & $\mathrm{I} .79$ & $2 \mathrm{I} .28$ \\
\hline PlayStation or other electronic games & 3.57 & 17.02 \\
\hline Internet Cafés & 5.36 & 10.64 \\
\hline Playing in the neighbourhood & 5.36 & 10.64 \\
\hline & & \\
\hline
\end{tabular}

(b) Categories with high rates of experienced leisure and low rates of desired leisure (EL $>D L$ )

For boys, experienced leisure activity rates are higher than the rates of desired leisure activities in $15 \%$ of the codes (six codes) (Table 6).

\section{Table 6.}

\begin{tabular}{|l|c|c|}
\hline Categories (Boys) & EL \% & DL \% \\
\hline Time on the computer & 74.07 & 39.34 \\
\hline Television & $61.1 \mathrm{I}$ & 18.03 \\
\hline Basketball or other sports & 59.26 & 52.46 \\
\hline Music & 48.15 & 39.34 \\
\hline Reading books or writing poems or prose & 37.04 & 3.28 \\
\hline Something else & 20.37 & 6.56 \\
\hline
\end{tabular}


We observe from the above table that boys spend a lot of time on the computer, watching television, playing basketball and listening to music $(74 \%-48 \%)$, less time on reading books $(37 \%)$, or choose to do something else.

As far as girls are concerned, experienced leisure activity rates are higher than desired leisure activity rates in $10 \%$ of the codes (four codes) (Table 7 ).

Table 7.

\begin{tabular}{|l|c|c|}
\hline Categories (Girls) & EL \% & DL \% \\
\hline Time on the computer & 76.79 & 34.04 \\
\hline Music & 66.07 & 31.91 \\
\hline Television & 55.36 & I4.89 \\
\hline Reading books or writing poems or prose & 48.21 & I9.15 \\
\hline
\end{tabular}

From the above table we can see that girls spend a lot of time on the computer, listening to music and watching television $(77 \%-55 \%)$, and less time reading books $(48 \%)$.

\section{(c) Categories with equal rates of experienced leisure and desired leisure $(E L=D L)$}

The categories for which rates of experienced and desired leisure are equal for boys ( $0 \%)$ are 'museums and other art and culture centres' and 'nothing', which represent $5 \%$ of the total number of categories, while for girls equal rates were obtained for the category 'nothing', which represents $2.5 \%$ of the total number of categories.

Based on the above information regarding the inequalities $(<,>)$ and equalities $(=)$ between experienced and desired leisure for boys and girls, we observe (in Table 8) that: (a) EL $<$ DL is very common for both boys and girls, representing $80 \%$ and $74 \%$ of the total number of categories respectively, which indicates that young people do not experience the activities they would like to develop, such as education, fun, sports and socialisation; (b) EL > DL is very uncommon for both boys and girls, representing $15 \%$ and $10 \%$ of the total number of categories respectively, the main choices being primarily passive activities, while (c) EL $=$ DL mainly for 'visiting museums and monuments', which has a zero rate.

Table 8. Percentage of total number of categories

\begin{tabular}{|l|c|c|}
\hline Relationship & Boys & Girls \\
\hline EL $<$ DL & 80 & 74 \\
\hline EL $>$ DL & I5 & I0 \\
\hline EL $=$ DL & 5 & 2.5 \\
\hline & $\mathrm{I} 00$ & \\
\hline
\end{tabular}

\section{Observations}

The pupils depicted their views of daily leisure using art as a medium. They arranged their compositions in two different ways. The first way focused on rendering moments of their leisure time with a human figure present in the picture and playing an important role, whereas the second way focused on 
artistically rendering leisure using objects that symbolize particular concepts. The young people described their artwork using poor vocabulary, with a strong tendency towards sarcasm and self-derision, and expressing bitterness, disappointment and a need for help.

As far as the study's goals are concerned, the deduction made was that irrespective of their sex, at least in the manner in which their views were rendered in their artwork, young people divide most of their available leisure time between the computer, listening to music, watching television and reading, with no rest and relaxation, the only difference between the sexes being that boys also play basketball. In a similar study, Fitzgerald et al. (1995) showed that there is a distinct difference in the leisure time preferences of boys and girls living in Dublin's poor neighbourhoods. Girls prefer going to clubs with friends, while boys prefer sports, watching television and playing video games. There is a large divergence between experienced and desired leisure. The children's daily schedule and especially their academic obligations limit opportunities for other activities, thus making experienced leisure very restrictive, as also indicated by the young people's verbal message that there is not enough time for activities other than schoolwork. Adolescent life seems to be full of restrictions, without many opportunities for sports, cultural education, shopping, hobbies, or to spend time with family or go on trips. De Róiste and Dinneen (2005) confirm this observation, having recognized that boys and girls mainly prefer activities such as watching television and going out with their peers. They recognized basic obstacles that boys and girls in Ireland were faced with and which as a rule were overcome by people from the lower classes.

The young people in the sample mainly illustrated passive activities (Internet, listening to music) and to a lesser extent active pursuits (sports, hobbies, going out with friends, coffee, drinks, watching films). This observation could indicate a lack of desire, time or social conditions for doing things with people and becoming involved in creative pursuits. It also indicates a tendency to avoid activities that broaden one's intellectual horizons and create opportunities for exposure to new people and situations.

While young people's desire to take part in activities that involve socializing is encouraging, their indication that 'time' is the main obstacle preventing them from becoming involved in such activities reveals their inability to evaluate their available free time and to use it efficiently, and also their tendency to use lack of time as an alibi. Perhaps it is not that they do not have enough time, but that they do not know how or do not want to actively manage it. It must, however, be noted that social class may significantly influence young people's choices in terms of how they manage their leisure. Matthews et al. (2000), Morrow (200I), Valentine et al. (1998) and Wyn and White, (1997) showed that for children from the lower classes, free time is associated with spending time on the streets, hence the term 'street-based leisure'. Most often, children and adolescents from the lower classes do not have the money to take part in structured leisure activities (Zeijl et al. 200I).

Thus, while the scientific exploration of young people's leisure spans a wide range of scientific fields and research personnel, the fact remains that the way that young people spend their free time is basically a social factor rather than a matter of personal choice, determined by each individual's needs. In other words, an adolescent's free time is 'burdened' with specific, mainly passive, activities dictated by the social environment (school environment, family).

Leisure is also prescribed by the lack of infrastructure (recreation areas at schools and universities, cultural centres, sports fields and courts, museums). It is important to note that young people do not experience in any way, and do not particularly wish to experience, religious, cultural or educational institutions such as going to church, religious events and the theatre, visiting museums and galleries and learning languages.

The adolescents' artwork gives rise to the speculation that their ideas and values are centred around school, without many opportunities to 'escape' or 'choose whatever they want'. Where the 'communication' code is concerned, the adolescents depicted it in terms of objects, such as computers, 
the Internet, mobile or other phones and television. In other words, the concept of communication is associated with technology. On the other hand, as far is interpersonal communication is concerned, the boys and girls depicted it by drawing other people in areas such as parks, coffee shops, the gym and football fields; communication with family was depicted as taking place in the kitchen with one parent present. Lastly, the 'enjoyment' code was drawn as occurring in places such as the cinema, in their own bedroom, at gym and in coffee shops (most of which were empty). In other words, enjoyment is associated with empty spaces and solitude.

Thus, if we were to draw a profile of an adolescent as deduced from this study, we could say that young people reveal a certain sense of solitude, with one parent present with them at home; they mainly communicate and have fun using technology and consuming Internet products (music, communication), and rarely take part in group activities that entertain, exercise the body and educate. Moreover, we know that leisure activities may have a positive (mainly) or negative impact on young children and adolescents (Larson and Verma, I999).

\section{References}

Bardin, L. (1977). L' analyse de contenu. Paris: PUF.

Byrne, T., Nixon, E., Mayock, P., \& Whyte, J. (2006). Free time and leisure needs of young people living in disadvantaged communities. Combat Poverty Agency.

Curley, K. (1990). 'Content Analysis'. In: E. Asher, The Encyclopedia of Language and Linguistics. Edinburgh: Pergamon Press.

Christodoulou, A. (2003). Semiotic and culture. Thessaloniki: University Studio Press.

Chtouris, S., Zissi, A., Papanis, E., \& Rontos, K. (2006). The state of youth in contemporary Greece. I4 (4), 309.

Coatsworth, J.D., Hiley Sharp, E., Palen, L.A., Darling, N., Cumsille, P. and Marta, E. (2005). 'Exploring Adolescent Self-Defining Leisure Activities and Identity Experiences Across Three Countries', International Journal of Behavioural Development, 29(5), 36I-70.

Danesi, M. (2000). Semiotics in Language education, Berlin New York: Mouton de Gruyter.

Danesi, M. \& Perron, P. (1999). Analysing cultures. An introduction and Handbook. Indiana University Press

De Róiste, A. and Dinneen, J. (2005). Young People's Views about Opportunities, Barriers and Supports to Recreation and Leisure, Dublin: National Children's Office.

Eccles, J. S., Barber, B. L., Stone, M. and Hunt, J. (2003). 'Extracurricular Activities and Adolescent Development'. Journal of Social Issues, 59, 865-889.

George, R. M. and Chaskin, R. J. (2004). What Ninth Grade Students in the Chicago Public Schools do in their Out of School Time. Chicago: Chapin Hall

Ghikopoulos, F., Christodoulou, A. (2007). 'Leasure in young people in Greece. A research'. In: Panepistimioupoli. Thessaloniki: AUTH, vol. 25 (in greek).

Grawitz, M. (198I). Methods des sciences socials. Paris : Dalloz.

Fitzgerald, M., Joseph, A. P., Hayes, M. and O’Regan, M. (1995). 'Leisure Activities of Adolescent Children', Journal of Adolescence, 18: 349-58.

Halliday, M.A.K. (1978) Language as social semiotic: The interpretation of language and meaning. London: Edward Arnold.

Hendry, L. B., Shucksmith, J., Love, J. G. and Glendinning, A. (1993). Young People's Leisure and Lifestyles. London: Routledge.

Hendry, L. B. and Kloep, M. (2003). 'Young People, Unprotected Time, and Overprotected Contexts: Resources, Challenges and Risks?'. In Colozzi, I. and Giovannini, G. (eds), Young People in Europe: Risk, Autonomy and Responsibilities. Italy: Franco Angeli s.r.1.

Hochschild, A. R. (1997). The Time Bind: When work becomes home and home becomes work. New York: Metropolitan Books.

Jewitt, C. and Oyama, R. (200I) 'Visual Meaning: a Social Semiotic Approach'. In Van Leeuwen, T. and Jewitt, C. (eds), Handbook of Visual Analysis, London, Sage, pp. 183-206. 
Kelly, J. R. (I98I). Leisure interaction and the social dialectic. Social Forces, 60 (2), 304-322.

Koronaiou, A., (1996). Sociology of Leisure. Athens, Nissos.

Kouthouris, H. (2006). 'Leisure, Recreation and Sports: Conceptual correlation of terms'. In: Inquiries in Physical Education \& Sport, 4 (I), 68-77. (in greek).

Krasanaki, G., (1984). Socio pedagogical leisure. Athens.

Lagopoulos, A.Ph, K. Boklund-Lagopoulou (1992) Meaning and Geography, Social Conception of the Region in Northern Greece. Berlin New York: Mouton de Gruyter.

Larson, R.W. and Verma, S. (1999). 'How Children and Adolescents Spend Time Across the World: Work, Play and Developmental Opportunities'. Psychological Bulletin, I25, 70I-36.

Lasswell, H., D. \& Leites, W. (I965). The Language of Politics: Studies in Quantitative Semantics. New York: MIT Press.

Mahoney, J. L. and Cairns, R. B. (1997). 'Do Curricular Activities Protect Against Early School Dropout?'. Developmental Psychology, 33, 24I-53.

Matthews, H., Limb, M. and Taylor, M. (2000). The Street as a Third Space in Children's Geographies: Playing, Living, Learning. London: Routledge.

Morrow, V. (200I). 'Networks and Neighbourhoods: Children's and Young People's Perspective'. In Social Capital for Health Services. London: HAD.

Mucchieli, R. (I998). L' analyse de contenu des documents et des communications. Paris: Les Editions ESF.

Myzirakis, G., (1997). Leisure of young people. Recreational and sports activities. Athens, National Centre for Social Research. (in greek).

Randviir A. \& Cobley P. (2010). Sociosemiotics. In Cobley P. (ed). Semiotics.

Roberts, K. and Parsells, G. (I994). 'Youth Cultures in Britain: Middle Class Take-Over'. Leisure Studies, I3, 33 48.

Robinson, J. P. \& G. Godbey (1997). Time for life: The Surprising Ways Americans Use Their Time. 2nd ed. Pennsylvania State University Press.

Rose, G. (2007). Visual Methodologies - An introduction to the Interpretation of Visual Materials, London, Sage.

Roth, W., Pozzer-Ardhenghi, L, \& Han, J. (2005). Critical graphicacy: Understanding visual representation practices in school science. Dordrecht, Springer.

Silbereisen, R. K. (2004). Adolescents: leisure-time activities. In International Encyclopedia of the Social \& Behavioral Sciences (pp. I22-I25).

Shaw, S. M., Caldwell, L.L. and Kleiber, D. A. (I996). 'Boredom, Stress and Social Control in the Daily Activities of Adolescents'. Journal of Leisure, 28, $274-293$.

Trainor, S., Delfabbro, P., Anderson, S., \& Winefield, A. (2010). 'Leisure activities and adolescent psychological well-being'. Journal of Adolescence, 33 (I), I73-186.

Triantafyllidis, M. (1998). Dictionary of Modern Greek Language. Manolis Triantafyllidis Foundation. (in greek).

United Nations World Youth Report 2005. (2005). Downloaded April I, 2010, from Youth and the United Nations: World program of action for youth: http://www.un.org/esa/socdev/unyin /wpayleisure.htm\#WYR2005.

Unsworth L, (2008) (ed) Multimodal Semiotics: Functional Analysis in Contexts of Education. London, Continuum.

Valentine, G., Skelton, T. and Chambers, D. (I998). 'Cool Places: an introduction to youth and youth culture'. In: T. Skelton, and G. Valentine (eds) Cool Places: Geographies of Youth Culture. London: Routledge.

Veron E. (I98I). La construction des événements. Paris: PUF.

Willinsky, J. (I990) The new literacy: Redefining reading and writing in the schools,. New York: Routledge Weber, R. (1990). Basic Content Analysis. Newbury Park: Sage.

Wyn, J. and White, R. (1997). Rethinking Youth. London: Sage Publications

Zeijl, E., DuBois-Reymond, M. and Te Poel, Y. (200I), 'Young adolescents' leisure patterns'. Society and Leisure, $2,379-402$. 
